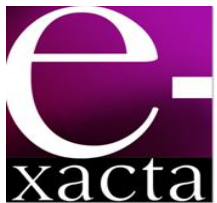

ISSN: 1984-3151

\section{O ENGENHEIRO E AS COMPETÊNCIAS NECESSÁRIAS AO DESEMPENHO PROFISSIONAL: UM ESTUDO DE CASO EM UMA IES PRIVADA DA REGIÃO METROPOLITANA DE BELO HORIZONTE}

\author{
THE ENGINEER AND THE NECESSARY COMPETENCIES FOR \\ PROFESSIONAL PERFORMANCE: A CASE STUDY IN A PRIVATE FACULTY \\ OF ENGINEERING OF THE METROPOLITAN AREA OF BELO HORIZONTE
}

Walnice Brandão Machado'; Talita Ribeiro Luz ${ }^{2}$

\footnotetext{
1 Mestranda em Administração- Faculdade Novos Horizontes. Graduação em Matemática pela UFMG, 1998. Professora do núcleo de Engenharia e Ciência da Computação- Faculdade Pitágoras. Belo Horizonte, MG. walniceb@gmail.com.

2 Doutora em Administração pela UFMG, 2001. Coordenadora do Curso de Mestrado Acadêmico em Administração- Faculdade Novos Horizontes. Belo Horizonte, MG.talita.luz@unihorizontes.br.
}

RESUMO: O objetivo norteador do presente estudo compreende descrever e analisar as contribuições que o curso de graduação em engenharia proporciona aos alunos para que eles possam desenvolver suas competências profissionais. Ao resgatar alguns aspectos históricos e do desenvolvimento da profissão no Brasil, o trabalho apresenta e analisa resultados de uma pesquisa realizada com discentes de uma instituição de ensino superior de Belo Horizonte. A pesquisa se caracteriza quanto aos fins como descritiva e quanto aos meios como um estudo de caso. Para a coleta dos dados utilizou-se questionários estruturados de acordo com o modelo de competências de Fleury \& Fleury e itens ligados às Diretrizes Curriculares Nacionais do curso de Graduação em Engenharia. A partir dos resultados fez-se possível inferir as percepções dos discentes em relação à contribuição que $O$ curso proporciona em sua formação profissional e o que eles consideram que seja uma instituição de ensino ideal. Tal análise também visa contribuir para uma melhoria no desenvolvimento de competências referentes ao curso para a inserção de profissionais engenheiros no mercado de trabalho.

PalAVRAS-CHAVE: Competências Profissionais. Engenheiro. Discentes. Ensino Superior.

ABSTRACT: The objective of the present study understands in describing and analyzing the contributions that the course of graduation in engineering provides to the pupils so that they can develop its professional competencies. When rescuing some historical aspects of the development of the profession in Brazil, present and analyze results of a research carried through with students of an institution of superior education of Belo Horizonte. The research characterizes as descriptive and as a case study. For the collection of the data one used structuralized questionnaires in accordance with the model of competencies of Fleury \& Fleury and with to the National Curricular Lines of direction of the course of Graduation in Engineering. From the results one becomes possible to infer the perceptions of the students in relation to the contribution that the course provides in its professional formation and what they consider that is an institution of ideal education. Such analysis also aims at to contribute for an improvement in the development of referring competencies to the course for the insertion of professional engineers in the work market.

KEYWORDS: Professional Competencies. Engineer. Learning. Superior Education.

\section{INTRODUÇÃO}

A sociedade brasileira da década de oitenta foi marcada por uma evolução da ciência e da tecnologia.
A aquisição de tecnologias prontas ia de encontro a uma luta contra o imperialismo tecnológico e científico dos países desenvolvidos. É nessa mesma década, e 
com base no mesmo espírito crítico, que se inicia a formação do novo engenheiro.

A profissão de engenheiro está diretamente associada a esse processo de evolução. Antes dele, as funções conceituais e de projeto eram competência do profissional do ofício, do mesmo modo que as funções de estimular as artes industriais mediante inovação (BRAVERMAN, 1974, p.118).

Neste sentido, o aprendizado incluía preparo em Matemática e nas propriedades e procedência dos materiais próprios do ofício, nas ciências físicas e no desenho mecânico. Mais importante que o preparo formal era o fato de que o ofício proporcionava um vínculo diário entre a ciência e o trabalho. Os engenheiros podiam ser considerados como parte importante do público científico, pois demonstravam interesse pela ciência e cultura, além daquele relacionado diretamente com o trabalho.

No contexto atual, o ensino de engenharia no Brasil, como parte do cenário mundial, demanda o uso intensivo da ciência e tecnologia exigindo profissionais altamente qualificados. Fleury e Fleury (2004) aferem que a qualificação pode ser definida "pelos requisitos associados à posição, ou ao cargo, pelos saberes ou estoque de conhecimentos da pessoa, os quais podem ser classificados e certificados pelo sistema educacional" (FLEURY; FLEURY, 2004, p. 28).

Ainda neste contexto, houve a necessidade de uma reforma educacional, em especial na formação superior, a fim de possibilitar a construção de competências profissionais. Para Ramos (2002) as reformas curriculares visam orientar a prática pedagógica organizada em torno da transmissão de conteúdos disciplinares, para uma prática voltada para a construção de competências.

Zarifian (2001) acredita que o conceito de competência extrapola o conceito de qualificação. Para o autor, a competência profissional está pautada na capacidade que um indivíduo dispõe de ir além das atividades prescritas, bem como por sua tomada de iniciativa diante de um determinado evento.

No que diz respeito à engenharia, o raciocínio analítico, bem como a competência para a resolução de problemas de ordem técnica ou não, deve ser desenvolvido ao longo de sua formação.

As competências se enriquecem também com todas as aptidões que se destacam dos saberes técnicos: saber-ser, saberes-sociais, capacidade de se comunicar, representações (ROPÉ; TANGUY, 2004, p.141).

Considerando os aspectos relacionados ao processo de ensino nos cursos de engenharia, o seguinte questionamento vem à tona: o ensino superior de engenharia desenvolve as competências profissionais necessárias aos seus discentes?

Para responder a tal questionamento, o presente estudo tem como objetivo geral descrever e analisar as contribuições que o curso de graduação em engenharia de uma instituição de ensino superior de Belo Horizonte proporciona aos alunos para que eles possam desenvolver suas competências profissionais.

Além do objetivo geral, foram traçados os seguintes objetivos específicos:

- Descrever, analisar e comparar as competências prescritas nas Diretrizes Curriculares Nacionais para curso de graduação em Engenharia com o modelo adotado (Fleury; Fleury, 2004);

- Descrever e analisar a contribuição do curso de graduação em engenharia para a formação profissional dos alunos, na percepção deles mesmos.

O perfil do engenheiro para Bazzo e Pereira (2008) está pautado em uma visão sistêmica, que Ihe confere um bom domínio da realidade física e também das atividades sociais e econômicas. Neste sentido, "o engenheiro adquire durante a sua formação uma idéia integrada de seu trabalho com o ambiente que o cerca" (BAZZO; PEREIRA, 2008, p. 84). 
O novo engenheiro deve ser capaz de propor soluções que sejam não apenas tecnicamente corretas, ele deve ter a ambição de considerar os problemas em sua totalidade, em sua inserção numa cadeia de causas e efeitos de múltiplas dimensões (BRASIL, 2002).

Justifica-se a relevância deste estudo pela necessidade de ressaltar importantes informações sobre a formação do discente em cursos de engenharia, apresentando contribuição para aprimoramento do ensino sob a perspectiva social.

Do ponto de vista acadêmico, este trabalho contribuirá para o desenvolvimento do curso investigado. As instituições de ensino superior no Brasil têm procurado, utilizando reformas periódicas de seus currículos, equacionar problemas no que se refere à formação dos alunos. Entretanto, essas reformas não têm sido inteiramente bem sucedidas, dentre outras razões, por privilegiarem a acumulação de conteúdos como garantia para a formação de um bom profissional.

Sob a perspectiva organizacional, o estudo possibilita o levantamento de informações importantes para a coordenação, bem como para a direção da instituição de engenharia submetida à pesquisa. Tais informações podem contribuir para uma melhoria do curso visando a um maior aproveitamento por parte de seus alunos e também à possibilidade de aumento na lucratividade da instituição.

\section{REFERENCIAL TEÓRICO}

O referencial teórico inicialmente se baseia em uma breve abordagem histórica da engenharia e do profissional engenheiro, e em seguida nos aspectos relevantes que envolvem o ensino superior, em especial a engenharia. Na sequência, aborda as diretrizes curriculares do curso em questão e finaliza com as competências como forma de enriquecer a formação deste mesmo profissional.

\subsection{A HistóRIA DA ENGENHARIA}

A história da engenharia confunde-se com a própria história da humanidade. Desde os primeiros artesãos da pré-história, mudanças significativas ocorreram. Houve um crescimento da diversidade técnica e com isso a necessidade de criação de estruturas teóricas que pudessem analisar tudo o que a técnica fosse capaz de abordar.

Durante essa evolução, ocorreu 0 aparecimento gradual de especialistas, que inicialmente não estavam preocupados com os fundamentos teóricos, mas sim em construir dispositivos, estruturas e instrumentos com base em experiências passadas.

Com a rápida expansão dos conhecimentos científicos e sua aplicação a problemas práticos, surge o engenheiro. Segundo Bazzo e Pereira (2008), o termo engenheiro, proveniente da palavra ingenium, que significa engenho ou habilidade, foi empregado primeiramente na Itália. No século XVIII esta designação passou a ser utilizada para identificar aqueles que utilizavam técnicas com base em princípios científicos. Antes disso, este termo designava aqueles que se dedicavam ao invento e à aplicação de engenhos.

O aparecimento formal do profissional de engenharia resultou de todo um processo de evolução ocorrido durante milhares de anos. Aos poucos a engenharia foi se estruturando, fruto do desenvolvimento da matemática.

De acordo com Holtzapple e Reece (2006), os gregos, com seus conhecimentos de matemática, contribuíram significativamente para o progresso da humanidade. $\mathrm{O}$ filósofo Pitágoras, no século VI a.C., foi um dos primeiros a aplicar argumentos puramente lógicos a princípios e axiomas. Na Alexandria egípcia, Euclides foi responsável por sistematizar a geometria e deu-lhe 
a forma que perdurou até o século XIX. Esta base matemática foi fundamental para 0 desenvolvimento dos cálculos, amplamente utilizados na engenharia.

O curso de engenharia no Brasil teve seu início formal, em 1792, no Rio de Janeiro com a Real Academia de Artilharia, Fortificação e Desenho - RAAFD (CUNHA, 1999). Este início foi marcado pela organização militar, já que havia grande preocupação com a defesa do país, ou seja, os primeiros engenheiros formados, entre a criação da academia, quando a RAAFD passou a se chamar Escola Central, eram necessariamente militares. Em 1874, a então Escola Central teve total desvinculação com a origem militar e foi transformada em Escola Politécnica (a atual Escola de Engenharia da Universidade Federal do Rio de Janeiro).

As primeiras escolas superiores de engenharia tinham uma atuação positivista com a valorização das ciências matemáticas e das disciplinas de natureza teórica. O ensino tinha como objetivo formar

(...) um letrado com aptidões gerais e um mínimo de informações técnico-profissionais, apto a preencher certos papéis da burocracia, na estrutura do poder político e no âmbito das profissões liberais. (KAWAMURA, 1981, p. 52).

Segundo Bazzo e Pereira (2008), a engenharia moderna é aquela que se caracteriza por uma forte aplicação de conhecimentos científicos à solução de problemas.

A engenharia moderna pode dedicar-se, basicamente, a problemas da mesma espécie que a engenharia do passado se dedicava, porém com uma característica distinta e marcante: a aplicação de conhecimentos científicos. (BAZZO; PEREIRA, 2008, p.70)

Nesse sentido, uma infinidade de teorias científicas aplicadas a problemas práticos contribuiu para o desenvolvimento de diversas áreas da engenharia. Conhecimentos sistematizados a respeito da natureza, como a estrutura da matéria, os fenômenos eletromagnéticos, a composição química dos materiais, as leis da mecânica e as modelagens matemáticas dos fenômenos físicos, passam a fazer parte da nova engenharia.

Com base em desenvolvimentos como esses, a engenharia evolui cada vez mais rapidamente, propiciando o aparecimento de novas escolas para a formação do profissional engenheiro.

\subsection{O ENSINO SUPERIOR E A ENGENHARIA}

A Lei de Diretrizes e Bases da Educação Nacional (LBD) é uma lei educacional que foi sancionada em 20 de dezembro de 1996 e fornece o direcionamento para a educação no Brasil.

A LDB define a educação num sentido abrangente, que engloba, além do processo de escolarização, a formação do indivíduo no trabalho e na convivência em geral. Assim reza a referida Lei:

Art. 1ํ A educação abrange os processos formativos que se desenvolvem na vida familiar, na convivência humana, no trabalho, nas instituições de ensino e pesquisa, nos movimentos sociais e organizações da sociedade civil e nas manifestações culturais.

$\S 1^{\circ}$ Esta Lei disciplina a educação escolar, que se desenvolve, predominantemente, por meio do ensino, em instituições próprias

$\S 2^{\circ}$ A educação escolar deverá vincular-se ao mundo do trabalho e à prática social (BRASIL, 1996).

As Instituições de Ensino Superior (IES) devem estimular a cultura, o conhecimento científico e a reflexão. Além disso, cabe às IES formar diplomados em várias áreas do conhecimento que sejam capazes de analisar os acontecimentos gerais acerca das atualidades que acontecem no mundo, sob a perspectiva de suas respectivas formações profissionais.

O ensino superior no Brasil vem apresentando um crescimento geral nas últimas décadas, sendo evidenciado pelo Gráfico 1. De acordo com o senso realizado anualmente pelo Instituto Nacional de Estudos e Pesquisas Educacionais Anísio Teixeira (INEP), o número de matrículas, nos cursos de 
graduação, aumentou em $7,1 \%$ de 2009 a 2010 e $110,1 \%$ de 2001 a 2010.

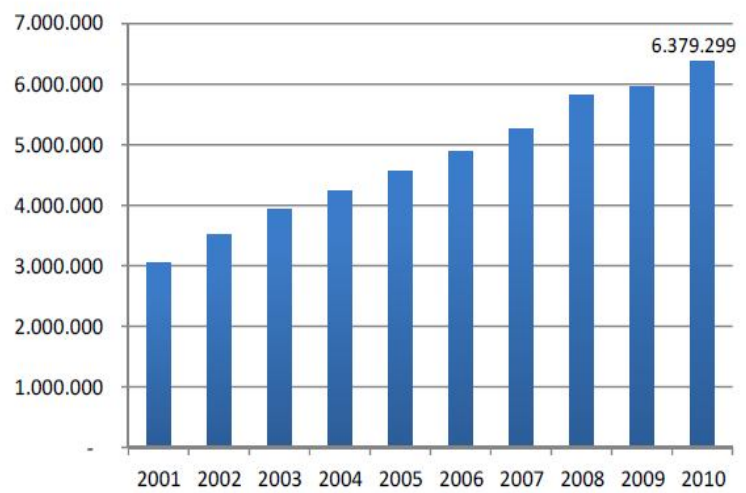

Gráfico 1: Evolução do Número de Matrículas em Cursos de Graduação no Brasil

Fonte: INEP:2010

Disponível em: http://portal.inep.gov.br/web/censo-daeducacao-superior/resumos-tecnicos

Ainda segundo o INEP, em 2010 o crescimento do número de cursos foi menor do que em 2009, mas foi maior do que a média 2001-2010. Em se tratando de cursos de Engenharia, o número de vagas praticamente triplicou durante a década, acompanhando um crescimento do número de cursos.

Em 2010 houve um significativo crescimento percentual de ingressantes nos cursos de engenharia, quando se compara com os anos anteriores. O percentual experimentado em 2010 é quase o dobro da média do crescimento ocorrido na década. Outro fator de destaque é a diminuição do número de vagas ociosas nos cursos. A taxa de ocupação das vagas, que vinha diminuindo durante a década, aumentou em 2010 (INEP, 2010).

O INEP apresenta os seguintes dados sobre o percentual de concluintes em cursos de Engenharia no período de 2001 a 2010, por meio do Gráfico 2.

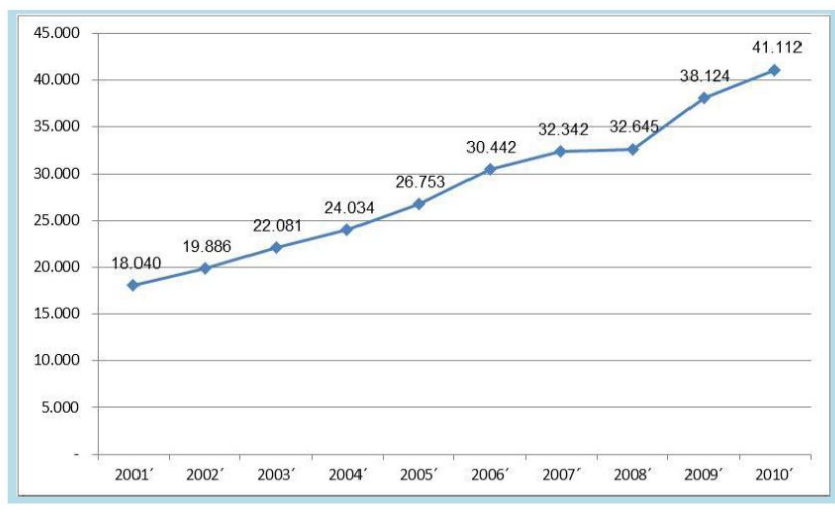

Gráfico 2: Total anual de concluintes em Engenharia

Fonte: INEP:2010

Disponível em: http://portal.inep.gov.br/web/censo-daeducacao-superior/resumos-tecnicos

Apesar do crescimento observado ao longo da década, de uma maneira geral, os quantitativos de concluintes em engenharia não estariam satisfazendo às necessidades do mercado. $A$ procura por engenheiros aumentou nos últimos anos, e a falta de profissionais faz com que alguns setores até precisem importar essa mão de obra mais especializada. Sem o número suficiente de profissionais e com o mercado de contratações aquecido, os cursos de engenharia vêm sendo cada vez mais procurados.

\subsection{Diretrizes Curriculares para Cursos DE ENGENHARIA}

A Resolução 11 do Conselho Nacional de Educação/Câmara de Educação Superior (CNE/CES), instituída em 11 de março de 2002, estabelece as Diretrizes Curriculares Nacionais do curso de Graduação em Engenharia, que devem ser consideradas pelas instituições de ensino superior na elaboração de sua estrutura curricular.

Conforme o artigo 3ำ (RES.11/2002, CNE/CES), o curso de Engenharia deve proporcionar, tanto ao aluno quanto ao profissional, a capacidade de absorver e desenvolver novas tecnologias, 
estimulando a sua atuação crítica e criativa na identificação e resolução de problemas, considerando os aspectos políticos, econômicos e sociais, que permeiam a sociedade.

As Diretrizes Curriculares para a formação do engenheiro têm por objetivo dotar o profissional dos conhecimentos requeridos para o exercício das seguintes competências e habilidades gerais, conforme artigo $4^{\circ}$ (RES.11/2002, CNE/CES):

I - aplicar conhecimentos matemáticos, científicos, tecnológicos e instrumentais à engenharia;

II - projetar e conduzir experimentos e interpretar resultados;

III - conceber, projetar e analisar sistemas, produtos e processos;

IV - planejar, supervisionar, elaborar e coordenar projetos e serviços de engenharia;

V - identificar, formular e resolver problemas de engenharia;

VI - desenvolver e/ou utilizar novas ferramentas e técnicas;

VI - supervisionar a operação e a manutenção de sistemas;

VII - avaliar criticamente a operação e a manutenção de sistemas;

VIII - comunicar-se eficientemente nas formas escrita, oral e gráfica;

IX - atuar em equipes multidisciplinares;

X - compreender e aplicar a ética e responsabilidade profissionais;

XI - avaliar o impacto das atividades da engenharia no contexto social e ambiental;

XII - avaliar a viabilidade econômica de projetos de engenharia;
XIII - assumir a postura de permanente busca de atualização profissional.

No que diz respeito à estrutura dos cursos de Engenharia, o artigo 5ำ (RES.11/2002, CNE/CES) aponta a necessidade de um projeto pedagógico que apresente como as atividades previstas irão possibilitar o desenvolvimento de competências e habilidades. O mesmo artigo enfatiza a necessidade de se reduzir o tempo em sala de aula, proporcionando um melhor aproveitamento do trabalho com os discentes.

O artigo $8^{\circ}$ (RES.11/2002, CNE/CES) ainda acrescenta que:

\begin{abstract}
A implantação e desenvolvimento das diretrizes curriculares devem orientar e propiciar concepções curriculares ao Curso de Graduação em Engenharia, que deverão ser acompanhadas e permanentemente avaliadas, a fim de permitirem os ajustes que se fizerem necessários ao seu aperfeiçoamento.

$\S 11^{\circ}$ As avaliações dos alunos deverão basear-se nas competências, habilidades e conteúdos curriculares desenvolvidos, tendo como referência as Diretrizes Curriculares.

$\S 2^{\circ}$ O Curso de Graduação em Engenharia deverá utilizar metodologias e critérios para acompanhamento e avaliação do processo ensinoaprendizagem e do próprio curso, em consonância com o sistema de avaliação e a dinâmica curricular definidos pela IES à qual pertence (BRASIL, 2002).
\end{abstract}

\subsection{COMPETÊNCIAS}

O conceito de competência segundo, Fleury e Fleury (2004), pode ser pensado como um conjunto de conhecimentos, habilidades e atitudes que só revela seu poder heurístico, quando aprendido no contexto de transformações do mundo do trabalho, seja nas empresas ou na sociedade.

A competência está associada à ação, ao desempenho e à eficiência e só pode ser avaliada mediante uma situação concreta. O termo no plural (competências) está vinculado aos "conteúdos particulares de cada qualificação em uma organização de trabalho determinada" (ROPÉ; TANGUY, 2004, p. 
22). Estas autoras consideram que as competências são propriedades instáveis, que necessitam ser submetidas constantemente à prova. Elas as diferenciam das qualificações por serem estas resultado do processo de titulação, menos instável, e comprovadas por meio de títulos ou diplomas.

Dutra (2008) afere que as competências podem ser adquiridas pelos agentes das relações de trabalho. Com isso, podem der definidas como saberes, conhecimentos, habilidades e atitudes e capacidade de transformação destes conceitos em ação e em resultados.

As competências ou a profissionalização no trato das relações do trabalho dependem, em primeiro lugar, da ocorrência dos eventos e das situações práticas colocadas. Essas situações geralmente envolvem conflitos dos agentes, capacidades de ação para encontrar saídas e encaminhamento aos problemas. (DUTRA,2008, p. 238)

As constantes mudanças no mercado de trabalho implicam um aprimoramento de recursos individuais necessários ao bom desenvolvimento do profissional. No contexto dessa afirmação, "a escola progressivamente aproximou-se do mundo das empresas por meio de cooperação de todos os tipos e também por revisões na maneira de pensar os conteúdos de ensino, organizar os modos de transmissão dos saberes e de avaliá-los" (ROPÉ; TANGUY, 2004, p.18).

A ideia de competência para Fleury e Fleury (2004) está vinculada a expressões tais como "saber agir", "mobilizar recursos", "integrar saberes múltiplos e complexos", "saber aprender", "saber se engajar", "assumir responsabilidades", "ter visão estratégica". Nesse sentido, os autores definem competência como "um saber agir responsável e reconhecido, que implica mobilizar, integrar, transferir conhecimentos, recursos, habilidades que agreguem valor econômico à organização e valor social ao indivíduo" (FLEURY; FLEURY, 2004, p. 30).
As competências profissionais propostas por Fleury e Fleury (2004) podem ser representadas conforme o Quadro 1.

\begin{tabular}{|c|c|}
\hline Competência & Significados \\
\hline Saber agir & $\begin{array}{l}\text { Saber o que e por que faz. } \\
\text { Saber julgar, escolher, decidir. }\end{array}$ \\
\hline Saber mobilizar & $\begin{array}{l}\text { Saber mobilizar recursos de } \\
\text { pessoas, sejam financeiros ou } \\
\text { materiais, criando sinergia entre } \\
\text { eles. }\end{array}$ \\
\hline Saber comunicar & $\begin{array}{l}\text { Compreender, processar, transmitir } \\
\text { informações e conhecimentos, } \\
\text { assegurando o entendimento da } \\
\text { mensagem pelos outros. }\end{array}$ \\
\hline Saber aprender & $\begin{array}{l}\text { Trabalhar o conhecimento e a } \\
\text { experiência. } \\
\text { Rever modelos mentais. } \\
\text { Saber desenvolver-se e propiciar o } \\
\text { desenvolvimento dos outros. }\end{array}$ \\
\hline $\begin{array}{c}\text { Saber } \\
\text { comprometer-se }\end{array}$ & $\begin{array}{l}\text { Saber engajar-se e comprometer- } \\
\text { se com os objetivos da } \\
\text { organização. }\end{array}$ \\
\hline $\begin{array}{l}\text { Saber assumir } \\
\text { responsabilidades }\end{array}$ & $\begin{array}{l}\text { Ser responsável, assumindo os } \\
\text { riscos e as consequências de suas } \\
\text { ações, e ser, por isso, reconhecido. }\end{array}$ \\
\hline Ter visão estratégica & $\begin{array}{l}\text { Conhecer e entender o negócio da } \\
\text { organização, seu ambiente, } \\
\text { identificando oportunidades, } \\
\text { alternativas. }\end{array}$ \\
\hline
\end{tabular}

QUADRO 1: Competências profissionais

Fonte: FLEURY; FLEURY, 2004, p.31.

Segundo Zarifian (2001), a competência profissional é uma responsabilidade do indivíduo em demonstrar que é capaz de trabalhar de maneira criativa e resolvendo problemas com iniciativa. Com isso ele certamente será reconhecido profissionalmente.

A competência profissional é uma combinação de conhecimentos, de saber fazer, de experiências e comportamentos que se exerce em um contexto preciso. Ela é constatada quando de sua utilização 
em situação profissional, a partir da qual é passível de validação (ZARIFIAN, 2001, p.66).

No que diz respeito ao sistema educacional, os saberes e as competências são construídos e aprimorados ao longo do processo de formação do discente.

A formação do engenheiro, em especial, está relacionada à capacidade de identificação e resolução de problemas e ao raciocínio analítico no enfrentamento de questões das mais diversas ordens.

De alguma forma, essa competência para tratar de problemas técnicos também se estende a questões sociais e cada vez mais tem influência na atuação do profissional da engenharia. A atitude de pensar precisa receber mais atenção, principalmente no que diz respeito à formação desse profissional, caminhando no sentido de formar engenheiros competentes.

\section{Metodologia}

A pesquisa realizada pode ser classificada quanto aos fins como descritiva.

A pesquisa descritiva expõe características de determinada população ou de determinado fenômeno. Pode também estabelecer correlações entre variáveis e definir sua natureza. Não tem compromisso de explicar fenômenos que descreve, embora sirva de base para tal explicação (VERGARA, 2010, p.47).

O método de pesquisa foi de caráter quantitativo. Segundo Vergara (2010) a pesquisa quantitativa utiliza procedimentos estatísticos para a análise dos dados.

No que diz respeito aos meios, o estudo de caso foi escolhido devido a sua capacidade de lidar com uma ampla variedade de evidências, entrevistas, questionários e observações. De acordo com Yin (2005, p.32), o estudo de caso é uma investigação empírica que analisa um fenômeno contemporâneo dentro de seu contexto da vida real, especialmente quando os limites entre o fenômeno e o contexto não estão claramente definidos.
O presente estudo tem por unidade de análise as competências profissionais dos alunos de engenharia de uma determinada instituição de ensino superior localizada na cidade de Belo Horizonte. Neste sentido, fez-se necessária a aplicação de um questionário aos estudantes do curso de graduação. O levantamento dos dados foi observado conforme o modelo de Fleury e Fleury (2004) e as diretrizes curriculares do curso de engenharia apresentados no referencial teórico deste estudo.

No processo de desenvolvimento da pesquisa, foram inicialmente aplicados 159 questionários a alunos do $3^{\circ}$ ao $8^{\circ}$ período do curso de Engenharia de Produção de uma IES de Belo Horizonte no período de novembro de 2012.

Quanto à estruturação, o questionário foi dividido em duas etapas: a primeira composta por perguntas sobre os dados sócio-demográficos, ajudando a descrever também as características quanto à formação e experiência profissional dos respondentes; a segunda referente às competências profissionais, segundo o modelo de Fleury e Fleury (2004), e as diretrizes do curso de engenharia.

Ressalta-se ainda que todos os itens foram avaliados em dois níveis de percepção distintos: o agrupamento ideal, que descreve a avaliação dos alunos quanto ao que deveria ser transmitido e aprendido na faculdade através do curso em relação à preparação e formação das competências profissionais e de valores contidos nas diretrizes do curso de engenharia; e o agrupamento real, que mensura o que está sendo efetivamente absorvido no decorrer do curso pelos aprendizes em relação às competências e diretrizes do curso, sob o ponto de vista dos próprios alunos. A escala de avaliação aplicada a todos os itens é do tipo likert e apresenta cinco opções de concordância para cada agrupamento (ideal e real). No momento da análise descritiva dos dados, foi utilizada a estatística 
univariada (medidas de posição) e bivariada (correlação).

\section{Apresentação dos Resultados}

Foram pesquisados 159 alunos, entre os quais a maioria (cerca de $65 \%$ do total amostral) é representada por indivíduos do sexo masculino, enquanto os $35 \%$ restantes são mulheres.

Os dados apresentados no Gráfico 3 permitem a visualização da distribuição da faixa etária dos respondentes. Verifica-se uma concentração expressiva de indivíduos em duas categorias que representam faixas etárias mais jovens. Enquanto mais de $71 \%$ dos alunos abordados apresentam idade entre 21 e 30 anos, uma outra parcela de apenas $11,5 \%$ é composta por indivíduos com mais de 36 anos de idade. Ressalta-se ainda que o percentual relativo aos respondentes com faixa etária inferior a 20 anos é de $1,9 \%$ somente.

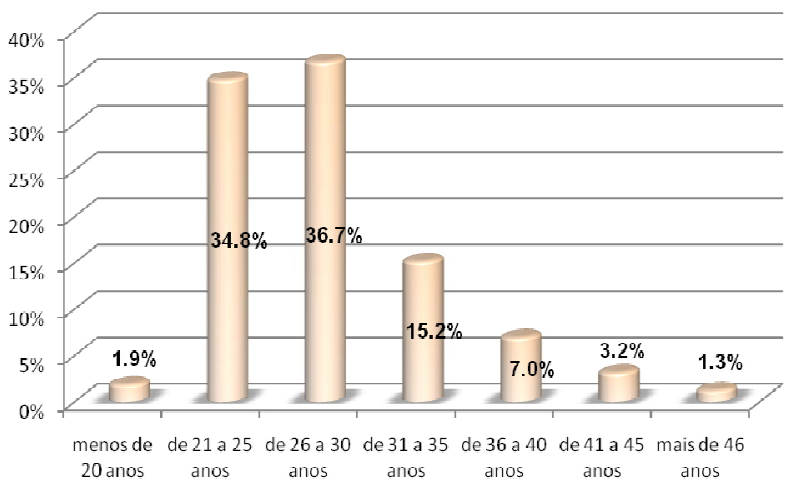

Gráfico 3 - Distribuição percentual em função da faixa etária dos respondentes

Quanto ao estado civil dos respondentes, a maioria expressiva da amostra (72\% do total de indivíduos) é composta por solteiros, enquantro pouco mais de $24 \%$ dos respondentes são casados. Uma parcela de aproximadamente $4 \%$ declarou estar em regime de união estável, ser divorciada ou separada, e nenhum indivíduo abordado na amostra indicou ser viúvo.
As distribuições percentuais expostas no Gráfico 4 correspondem ao tempo de trabalho na área de engenharia, incluindo-se os períodos de estágios. Constata-se que, enquanto $32,3 \%$ dos respondentes possuem menos de 6 meses de atuação na área, o percentual correspondente àqueles que apresentam mais de 31 meses de experiência no mesmo contexto é de aproximadamente $24 \%$ do total amostral. Outra faixa com concentração razoavelmente significativa diz respeito ao tempo de 13 a 18 meses de experiência, que apresenta $17,7 \%$ dos dados. Já as demais categorias listadas possuem frequências relativas sempre inferiores a $10 \%$ do total.

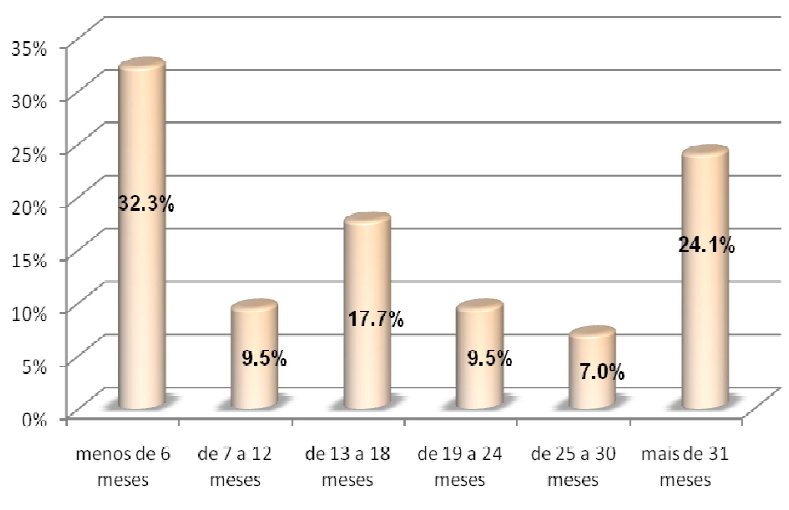

Gráfico 4 - Distribuição percentual dos respondentes quanto ao tempo de trabalho na área de engenharia

Os resultados apresentados no Gráfico 5 são concernentes ao tempo total de trabalho que os alunos abordados possuem. Nota-se que uma categoria se destaca das demais por apresentar um percentual significativamente elevado. Esta categoria corresponde justamente à faixa que representa maior grau de experiência, ou seja, mais de 31 meses de tempo total de trabalho e apresenta percentual de aproximadamente $67 \%$ do total amostral. Já as demais categorias listadas possuem frequências relativas próximas (sempre entre $5 \%$ e $10 \%$ ) e pouco expressivas diante daquela já descrita.

e-xacta, Belo Horizonte, v. 6, n. 2, p. 33-44. (2013). Editora UniBH Disponível em: www.unibh.br/revistas/exacta/ 


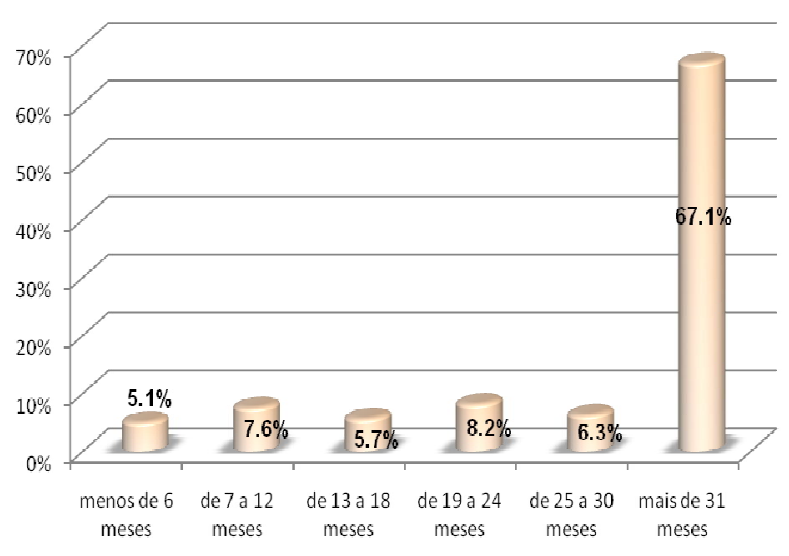

Gráfico 5 - Distribuição percentual dos respondentes quanto ao tempo de trabalho

Observando o Gráfico 6 é possível analisar os dados quanto ao período que os respondentes estão cursando. Observa-se que a quantidade de alunos cursando o oitavo período é bastante díspar das demais, concentrando mais da metade dos dados. Por outro lado, a concentração percentual referente ao terceiro período é de apenas $3,2 \%$, e mesmo as demais categorias não possuem frequência demasiadamente significativa como aquela já citada para o último período listado.

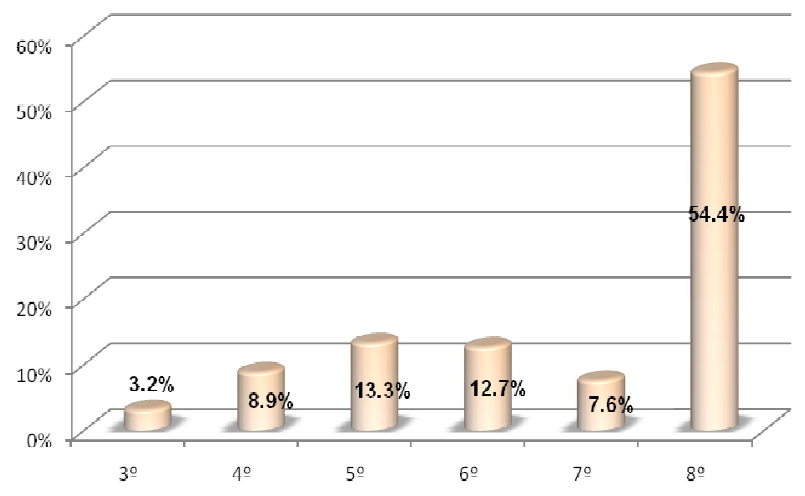

Gráfico 6 - Distribuição percentual dos respondentes em função do período do curso

Quanto aos respondentes possuirem outra formação, seja técnica ou graduação, constatou-se um razoável equilíbrio entre as duas categorias, sendo a maioria dos dados representada por alunos que possuem outra formação técnica (pouco menos de $55 \%$ do total). Os indivíduos que declararam não possuir tal formação compõem cerca de $45 \%$ da amostra.

O estudo univariado contém seus resultados expostos no Gráfico 7, os quais são referentes às competências profissionais no campo "ideal" e "real". Foram consideradas as sete variáveis apresentadas no modelo proposto por Fleury e Fleury (2004) e considerou-se a escala de cinco pontos utilizada no questionário.

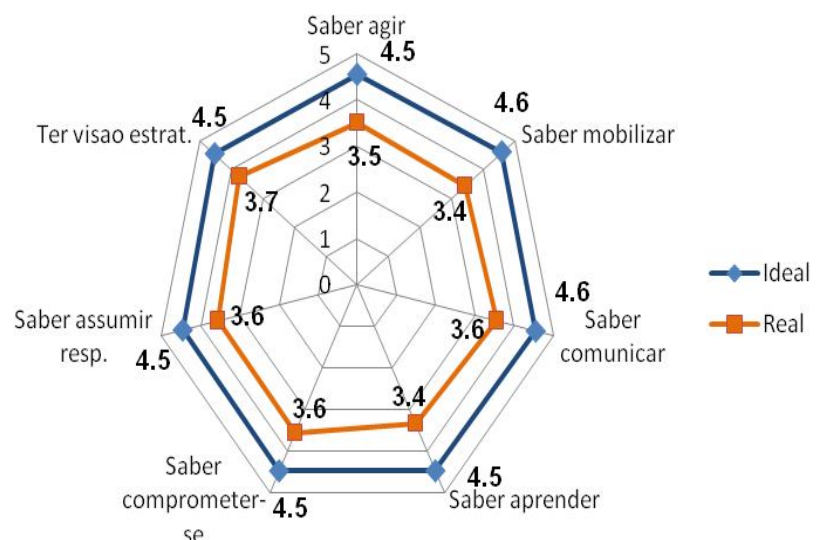

Gráfico 7 - Aspecto comparativo das médias relativas às competências profissionais segundo Fleury $\mathrm{e}$ Fleury(2004)

O Gráfico 7 permite a visualização dos valores médios fornecidos pelos respondentes sob um aspecto comparativo entre os grupos "ideal" e "real" para as competências profissionais. Evidencia-se na figura a disparidade entre as linhas de dados referentes aos dois grupos em questão, com pouca variação dos valores ao se observar cada grupo individualmente. As características presentes no gráfico indicam a diferença entre o que os alunos esperam aprender no curso quanto às competências profissionais e o que está sendo realmente absorvido.

O estudo de correlações foi efetuado considerando os cruzamentos entre as competências profissionais e os 
itens que compõem as diretrizes do curso de engenharia, tanto no aspecto ideal quanto no real. $\mathrm{O}$ objetivo geral era detectar tendências de opinião entre os respondentes na relação estabelecida entre as variáveis associadas no teste.

No campo ideal, todas estas relações denotaram certa coerência no critério de avaliação dos respondentes, mostrando que as suas expectativas quanto às competências profissionais se assemelham muito àquelas referentes aos itens das diretrizes do curso.

Os resultados obtidos para o "real" foram análogos àqueles realizados para as correlações do grupo "ideal". Em outras palavras, as variáveis colocadas sob testes apresentaram sempre uma relação de correspondência. Assim, verificou-se que os respondentes que conferem avaliações, sejam elas positivas ou negativas, a respeito do que está sendo efetivamente absorvido durante o curso para as competências profissionais, tendem a apresentar o mesmo padrão para a avaliação do aprendizado real a respeito dos itens que compõem as diretrizes do curso.

\section{Considerações FinaIS}

A educação superior, como parte do processo educacional, visa ao desenvolvimento da aprendizagem usando ações de integração entre as instituições e seus discentes.

O presente estudo objetivou descrever e analisar as contribuições que o curso de graduação em engenharia de uma instituição de ensino superior de Belo Horizonte proporciona aos alunos para que eles possam desenvolver as competências profissionais prescritas nas Diretrizes Curriculares Nacionais para o curso de graduação em Engenharia.

Para tanto, o questionário aplicado estabeleceu uma comparação entre o que é considerado ideal e o que realmente está sendo absorvido ao longo do curso, na percepção dos próprios discentes.

Vale ressaltar que o período cursado pelo discente tem uma expressiva influência com relação às expectativas, no que diz respeito ao aprendizado e à instituição. Os alunos com menos tempo de curso apresentam maiores anseios neste aspecto.

Outro ponto a ser considerado é que os respondentes com um menor tempo de trabalho na área de engenharia ainda apresentam dificuldades na percepção das competências profissionais, em relação aos que já atuam na área há mais tempo.

Considerando o campo ideal, as respostas concentraram-se no valor mais alto da escala em quase sua totalidade. No entanto, o campo real apresentou uma expressiva variação, o que pode indicar uma falta de percepção dos entrevistados em verificar até que ponto o curso tem contribuído para o desenvolvimento das competências profissionais.

As diretrizes curriculares para o curso de engenharia propõem a formação de um profissional apto a desenvolver novas tecnologias com uma visão crítica e criativa, considerando aspectos políticos, econômicos e sociais, como forma de atender às necessidades do mercado.

Às instituições de ensino superior cabe o papel de proporcionar ao discente condições necessárias ao desenvolvimento do aprendizado. A utilização de uma metodologia adequada aliada à dinâmica curricular proposta pela própria instituição faz parte dessa produção de conhecimento.

Os resultados obtidos na análise deste estudo poderão ser de grande valia, tanto para o curso quanto para a instituição pesquisada. Tais informações podem contribuir para uma melhoria na formação dos seus discentes, no que tange ao processo de ensino e aprendizagem e ao desenvolvimento das competências profissionais 
necessárias para a inserção de profissionais engenheiros no mercado de trabalho. Podem também contribuir para que outras IES repliquem esta pesquisa, tendo por objetivo conhecer a percepção dos discentes a respeito da formação que Ihes está sendo proporcionada.

\section{REFERÊNCIAS}

BAZZO, A. W.; PEREIRA, L. T. V.; Introdução à engenharia: conceitos, ferramentas e comportamentos. Florianópolis: Ed. Da UFSC, 2008.

BRASIL, Biblioteca geral da câmara dos deputados. $L D B$ - Lei de Diretrizes e Bases da Educação Nacional. 5a edição. Brasília: 2010. Disponível em: http://bd.camara.gov.br/bd/bitstream/handle/bdcamara/ 2762/ldb 5ed.pdf. Acesso em: outubro de 2012.

BRASIL, Instituto Nacional de estudos e pesquisa educacionais Anísio Teixeira (INEP). Senso da educação Superior 2010. Disponível em: http://portal.inep.gov.br/web/censo-da-educacaosuperior/resumos-tecnicos. Acesso em: outubro de 2012.

BRASIL, Ministério da Educação. Diretrizes Curriculares Nacionais do Curso de Graduação em Engenharia. Conselho Nacional da Educação. Resolução CNE/CES. 11/2002. Disponível em: http://portal.mec.gov.br/cne/arquivos/pdf/CES112002.p df. Acesso em: outubro de 2012.

BRAVERMAN, H. Principais efeitos da gerência científica. Trabalho e capital monopolista: a degradação do trabalho do século XX. 3.ed. Rio de Janeiro: Zahar, 1974. cap. 2-5, p. 60-123.

CUNHA, F. M. A formação do engenheiro na área humana e social: um estudo de caso no curso de engenharia industrial elétrica do CEFET-MG. 1999. Dissertação (Mestrado em Tecnologia - Área de concentração em Educação Tecnológica) - Centro Federal de Educação Tecnológica de Minas Gerais, Belo Horizonte.
DUTRA, J. S., FLEURY, M. T. L., RUAS, R. Competências: conceitos, métodos e experiências. São Paulo: Atlas, 2008.

FLEURY, A. C; FLEURY, M. T. L. Estratégias empresariais e formação de competências: um quebra-cabeça caleidoscópico da indústria brasileira. $3^{\underline{a}}$ edição. São Paulo: Atlas, 2004.

FREIRE, P. Pedagogia da autonomia: saberes necessários à prática educativa. São Paulo: $\mathrm{Paz}$ e Terra, 1998.

HOLTZAPPLE, M. T.; REECE, D. W. Introdução à engenharia. Rio de Janeiro: LTC, 2006.

KAWAMURA, L. K. Engenheiro: trabalho e ideologia. São Paulo: Ática, 1981.

RAMOS, M. N. A pedagogia das competências: autonomia ou adaptação? 2.ed. São Paulo: Cortez, 2002.

ROPÉ, F.; TANGUY, L. (Orgs.). Saberes e competências: 0 uso de tais noções na escola e na empresa. 5.ed. Campinas: Papirus, 2004.

VERGARA, S. C. Projetos e relatórios de pesquisa em Administração. São Paulo, Atlas, 2010.

YIN, R. K. Estudo de caso: planejamento e métodos. 3.ed. Porto Alegre: Bookman, 2005.

ZARIFIAN, P. Objetivo competência: por uma nova lógica. São Paulo: Atlas, 2001. 